\title{
Near-ubiquity of ice-edge blooms in the Arctic
}

\author{
M. Perrette ${ }^{1, *}$, A. Yool ${ }^{1}$, G. D. Quartly ${ }^{1}$, and E. E. Popova ${ }^{1}$ \\ ${ }^{1}$ National Oceanography Centre; Univ. of Southampton Waterfront Campus, European Way, Southampton SO14 3ZH, UK \\ *now at: Potsdam Institute for Climate Impact Research (PIK), Telegrafenberg A31, 14412 Potsdam, Germany
}

Received: 22 September 2010 - Published in Biogeosciences Discuss.: 4 November 2010

Revised: 10 February 2011 - Accepted: 15 February 2011 - Published: 25 February 2011

\begin{abstract}
Ice-edge blooms are significant features of Arctic primary production, yet have received relatively little attention. Here we combine satellite ocean colour and sea-ice data in a pan-Arctic study. Ice-edge blooms occur in all seasonally ice-covered areas and from spring to late summer, being observed in 77-89\% of locations for which adequate data exist, and usually peaking within 20 days of ice retreat. They sometimes form long belts along the ice-edge (greater than $100 \mathrm{~km}$ ), although smaller structures were also found. The bloom peak is on average more than $1 \mathrm{mg} \mathrm{m}^{-3}$, with major blooms more than $10 \mathrm{mg} \mathrm{m}^{-3}$, and is usually located close to the ice-edge, though not always. Some propagate behind the receding ice-edge over hundreds of kilometres and over several months, while others remain stationary. The strong connection between ice retreat and productivity suggests that the ongoing changes in Arctic sea-ice may have a significant impact on higher trophic levels and local fish stocks.
\end{abstract}

\section{Introduction}

The classical picture of Arctic ice-edge phytoplankton blooms found in the literature - mainly based on cruise transects - is of a long but narrow $(20-100 \mathrm{~km})$ band along the ice-edge, moving northward as the ice breaks up and melts over spring and summer (Sakshaug and Skjoldal, 1989). They differ from more traditional open-water blooms with respect to the nature of water column stratification, here induced primarily by freshwater input instead of solar heating. When sea-ice breaks up and melts, there is an input of freshwater to the surface that induces strong stratification. Another causal factor is increased solar irradiance at the surface as ice cover shrinks. Since irradiance is typically sufficient

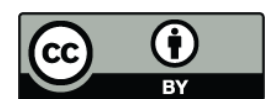

Correspondence to: M. Perrette (mahe.perrette@pik-potsdam.de) by the time ice cover recedes, Sverdrup's (1953) criterion of a mixed layer shallower than the critical depth is met, making the light regime suitable for phytoplankton growth. Ice-edge blooms are generally understood as short-lived phenomena that quickly strip out the nutrients of the shallow (15-35 m) surface mixed layer characteristic of seasonally ice-covered waters (Niebauer, 1991). The area located between the multiyear ice and maximal extent is the seasonal ice cover, and this forms the subject of this study, with a particular focus on the marginal ice zone (MIZ), which is the region of recent ice melt.

Ice-edge phytoplankton blooms have been detected from cruises in many locations including Bering Sea (Alexander and Niebauer, 1981; Niebauer et al., 1995), Chukchi and Beaufort Seas (Hill et al., 2005; Sukhanova et al., 2009), Canadian Archipelago (Klein et al., 2002; Tremblay et al., 2006), Greenland Sea (Smith et al., 1997), Barents Sea (Luchetta et al., 2000; Hegseth and Sundfjord, 2008), and also in the Southern Ocean (Smith and Nelson, 1985). In the Barents Sea and on the Bering Shelf they are thought to account for $50-65 \%$ of annual primary production (Sakshaug, 2004). Indications of ice-edge blooms had been noted in ocean colour imagery from the Coastal Zone Color Scanner (e.g. Maynard, 1986; Maynard et al., 1987; Mitchell et al., 1991; Kögeler and Rey, 1999) but detailed investigations were not possible on account of its poor sampling due to limited onboard storage, and underestimation problems close to ice due to a "ringing effect" as the scan line moved from bright to dark features (Mitchell et al., 1991). The launch of the SeaWiFS in 1997 ushered in a new era of long-term continuous ocean colour observations, with the whole globe sampled every two days, albeit that in some places cloud frequently obscures the surface. However, the potential of the SeaWiFS archive for the investigation of ice-edge blooms has only led to a few publications to date (e.g. Arrigo and van Dijken, 2004), and thus a primary aim of this study is to fill this gap and investigate their existence at the large

Published by Copernicus Publications on behalf of the European Geosciences Union. 


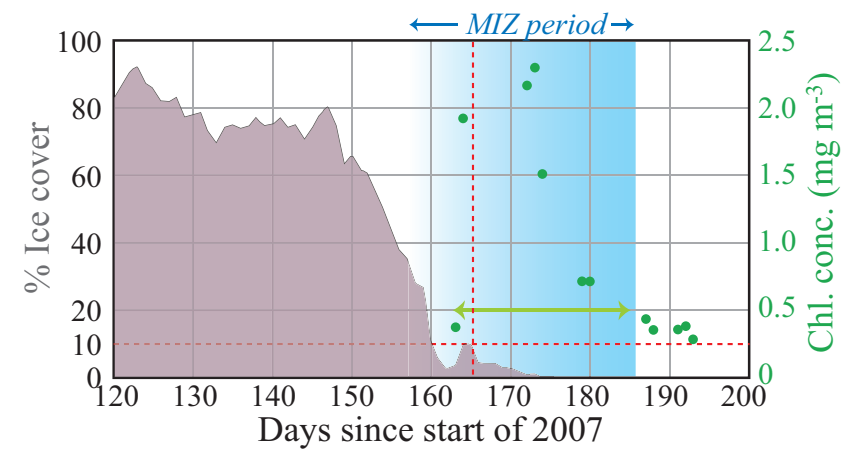

Fig. 1. Illustration of data coverage for an example location in Baffin Bay, showing our definition of the MIZ period and the existence of an ice-edge bloom. Our MIZ period is up to 20 days after seaice concentration is durably below $10 \%$, and a bloom is registered when chlorophyll concentration exceeds $0.5 \mathrm{mg} \mathrm{m}^{-3}$.

scale. It is essential to understand the dynamics of phytoplankton blooms and their future evolution because of their impact on primary production, which in turn affects higher trophic levels (Hunt et al., 2002). Bloom dynamics also play a major role in carbon sequestration and export (Wassmann et al., 2008), and there is considerable uncertainty about the changes they will undergo in response to further ice shrinkage in the next few decades (Sakshaug, 2004; Tremblay and Gagnon, 2009). Satellite observations provide a synopticscale picture of these blooms, necessary for the development of a theoretical understanding that will permit their future forecasting.

\section{Sources of satellite data}

Chlorophyll concentrations are obtained from Level 3, daily SeaWiFS ocean colour data ${ }^{1}$ derived using the OC4v4 empirical algorithm, and are provided on a Cartesian, $1 / 12^{\circ}$ grid (corresponding to $9 \mathrm{~km}$ or smaller). Sea-ice concentrations are obtained from National Snow and Ice Data Center (NSIDC), and are based on daily passive microwave radiometry with the Bootstrap algorithm (Comiso, 1999). Sea-ice fields are provided on a polar stereographic grid, at $25 \mathrm{~km}$ resolution; here we interpolate them onto the chlorophyll grid using a nearest neighbour scheme (sensitivity tests find that the type of interpolation applied has little influence on the results; results not shown). The SeaWiFS and NSIDC datasets both cover the period 1998-2007.

Following Pabi et al. (2008), we set the boundary between sea-ice and open-water as a sea-ice concentration of $10 \%$. This value is considered reliable for this type of measurement (Worby and Comiso, 2004), and this threshold approximately corresponds to the value above which ocean colour data are

\footnotetext{
${ }^{1}$ http://oceandata.sci.gsfc.nasa.gov/SeaWiFS/Mapped/Daily/ chlor/
}

flagged as contaminated by sea-ice and chlorophyll values are therefore unavailable.

We define the MIZ as the region for which ice concentration is reduced to consistently less than $10 \%$ within the last 20 days (i.e. no new growth of sea-ice or import of drifting ice until the end of the season; Fig. 1). The temporal coverage of ocean colour sensors is poor at high latitudes with gaps that can last for several weeks, especially during the ice-melt period. There is an average of five observations per pixel in these first 20 days. This relatively poor coverage is in part the result of heavy fog that forms at this time of the year as relatively warm water is exposed to the colder atmosphere. This phenomenon adds to the effect of clouds and ice on masking the sea surface. Even when available, the quality of ocean colour data may be further affected by sea-ice present at the subpixel scale (Bélanger et al., 2007) and by Coloured Dissolved Organic Material (CDOM) that is abundant in Arctic waters. The globally-calibrated, empirical algorithm OC4v4 may therefore include large errors in chlorophyll retrieval (Cota et al., 2004; Gregg and Casey, 2004), although its performance remains comparable to the regionally-tuned algorithm OC4L (Wang and Cota, 2003; Matsuoka et al., 2005). Those deficiencies are, however, not critical to this study of blooms, since the biases are consistent in time and space and thus relative changes are meaningful. Subpixel contamination and the adjacency effect do indeed occur near the iceedge but, to our knowledge, separately of geographical location. All of the data that we analyzed were selected on the basis of their proximity to the ice-edge, and should therefore be affected equally. However, we recognize that variations in the availability of data within the 20-day MIZ period, in relation to cloud and fog cover, may force sampling at varying distances from the ice-edge. This may therefore introduce a bias with respect to the possible contamination identified by Bélanger's work, and more importantly with respect to the bloom development stage. Our assumption here is that the scale of such variability is small and that it does not affect the interpretation of observed patterns at the pan-Arctic level, although careful interpretation of the results is needed for the locations where this could not be verified (e.g. the high Arctic). Regarding CDOM, areas known for having high load are reported throughout the text. Fortunately, a high precision in the measurements is largely secondary in much of the analysis conducted here, since blooms are readily identified by order of magnitude changes over more than one pixel.

Some aspects of this work however involve quantitative analysis that is more sensitive to the quality of chlorophyll data and requires a closer inspection. The problem of subpixel contamination by sea-ice has been recently addressed in the literature (Bélanger et al., 2007), and results suggest that chlorophyll may be overestimated at moderate to high concentration $\left(>0.5 \mathrm{mg} \mathrm{m}^{-3}\right)$, and underestimated at low concentration $\left(0.05 \mathrm{mg} \mathrm{m}^{-3}\right)$. This effect is amplified by the presence of CDOM. Bélanger et al. (2007) report however that only a small fraction of pixels are affected. 

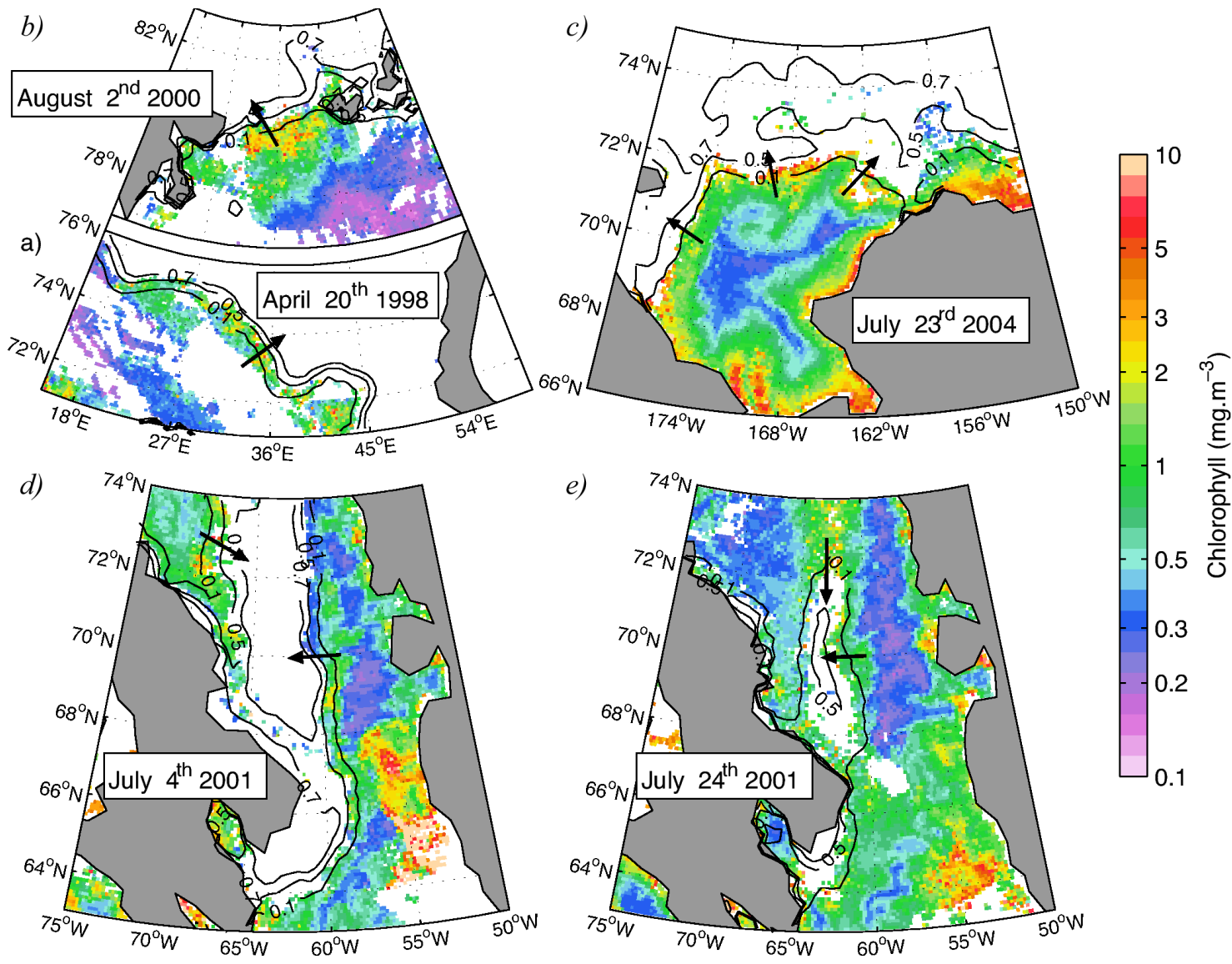

Fig. 2. Examples of ice-edge phytoplankton blooms and their evolution in different marginal seas of the Arctic. Barents Sea in (a) April $1998\left(71-75^{\circ} \mathrm{N}\right)$ and (b) August $2000\left(79-81^{\circ}\right.$ N). (c) Chukchi Sea in July 2004. (d, e) Davis Strait and Baffin Bay in July 2001 showing the change that occurs in 20 days. All images are 5-day composites of chlorophyll (SeaWiFS) overlaid with sea-ice contours (NSIDC) at $10 \%, 50 \%$ and $70 \%$. White areas are missing chlorophyll data. Arrows indicate the propagation direction of the ice-edge, and hence of the blooms.

A chlorophyll threshold of $0.5 \mathrm{mg} \mathrm{m}^{-3}$ has been defined in our work to identify the blooms (see next section), based on visual observation and knowledge of bloom dynamics. It is worth noting that this chlorophyll level is less affected by subpixel contamination, and is therefore well suited to discriminate between background chlorophyll concentration and blooming conditions. Automatic flagging of pixels during the processing of water-leaving radiance may fail to detect such contamination (Bélanger et al., 2007), and comparison with another chlorophyll dataset (MODIS) indicates that detection of subpixel contamination and more generally retrieval of chlorophyll in Arctic water varies between sensors. Visual inspection (not shown) reveals indeed that at certain locations and times SeaWiFS data appears noisy (likely the effect described above) while this is not the case for MODIS, which is smoother and has in general lower chlorophyll values. MODIS has however a very poor coverage in the Arctic (half as many observations as SeaWiFS in the MIZ on average, not shown), which is possibly a result of using stricter quality control. MODIS data are used in this study to provide an independant, conservative estimate for bloom occurrence, recognizing that the lack of valid data in MODIS is a strong bias toward underestimation. Due to the substantial area of Arctic coastline being potentially affected by the riverine input and spurious effect of CDOM we excluded coastal areas from the analysis.

\section{Illustrative examples}

This section describes the occurrence of major ice-edge phytoplankton blooms in various regions, and provides an overview of their diversity in shape, intensity and timing. All images shown in this section are 5-day composites to overcome data gaps.

The Barents Sea is one of the most studied regions regarding ice-edge phytoplankton blooms, lying between Norway and the Svalbard Archipelago. An early bloom occurred in 1998 at the southernmost edge of the ice $\left(71^{\circ}-75^{\circ} \mathrm{N}\right)$ that 

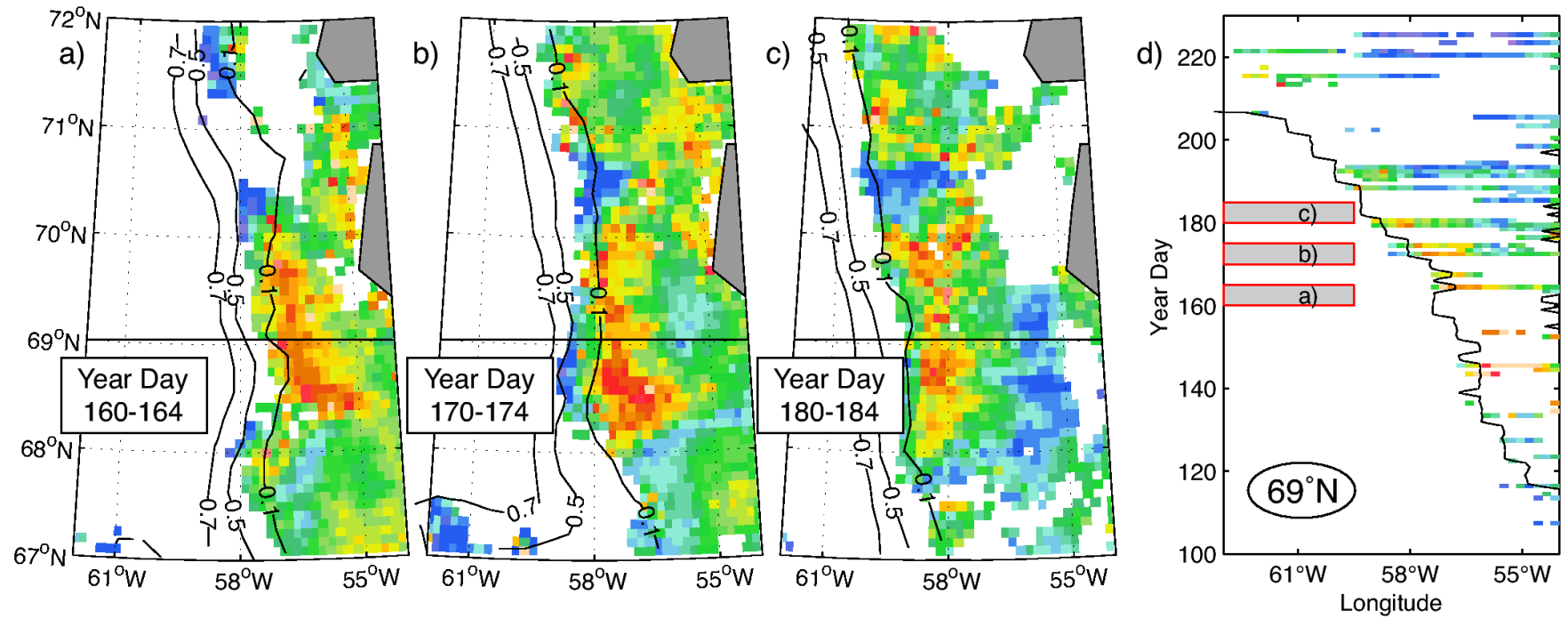

Fig. 3. An example of the propagation of an ice-edge phytoplankton bloom west of Greenland over a 25-day period (a, b, c). The three images are 5-day composites of chlorophyll (SeaWiFS) overlaid with sea-ice contours (NSIDC) at 10\%, 50\% and 70\%. White areas are missing chlorophyll data. Panel (d) shows a corresponding Hovmöller diagram at $69^{\circ} \mathrm{N}$ that illustrates the progression of the 2007 bloom, and shows that this can be followed for many months despite large data gaps. The black line indicates the $10 \%$ sea-ice contour. Colour code is the same as Fig. 2.

propagated over $\sim 100 \mathrm{~km}$ in a month (Fig. $2 \mathrm{a}$ ). Figure $2 \mathrm{~b}$ shows a bloom occurring in 2000, much further north at $80^{\circ} \mathrm{N}$ and three and a half months later. These illustrate the length of the melt season and size of the seasonal ice cover in this region. Here, major blooms $\left(>4 \mathrm{mg} \mathrm{m}^{-3}\right)$ are not seen propagating over the whole region, but are rather manifested as transient local increases in chlorophyll. Smaller blooms usually propagate over greater distances, following the classical view depicted by Sakshaug and Skjoldal (1989). Most blooms form a band of usually less than $100 \mathrm{~km}$ width, with chlorophyll values near the ice edge distinctly greater than in post-bloom conditions $\left(<0.4 \mathrm{mg} \mathrm{m}^{-3}\right)$.

The Chukchi Sea (Fig. 2c) in the Pacific sector presents the same type of ice retreat northwards, but the northernmost iceedge is now at $72^{\circ} \mathrm{N}$, the same latitude as the southern Barents Sea. Here (23 July 2004), blooms occur all along the iceedge in a very long band, forming a circular arc that grows as the ice melts further away, leaving behind post-bloom conditions with very low surface chlorophyll concentration. The Bering Strait, visible at the south of the region, has continuous blooms due to the inflow of high-nutrient waters (Sakshaug, 2004). High values along the coast should be viewed with caution since these waters are likely to be contaminated by CDOM from rivers.

Sea-ice retreat is not always northward, as exemplified in the region west of Greenland: Baffin Bay and Davis Strait (Figs. 2d-e). The composites are 20 days apart and show the course of the ice retreat, shrinking both westward from Greenland and south-eastward from the north. The ice remains in the middle of the bay before melting completely, leaving behind a trace of chlorophyll, a sign of the ice-edge bloom's presence. The ice-edge blooms thus follow the retreating sea-ice whatever its direction of propagation, indicating the strength of the biophysical coupling with sea-ice.

\section{A bloom in motion}

One of the main characteristics of an ice-edge bloom is its local transience and its wave-like propagation, sometimes over great distances, as illustrated by three 5 -day composites at intervals of 10 days (Fig. 3a-c). This massive bloom was observed off the west coast of Greenland and started some time prior to Fig. 3a when the sea-ice broke up, and disappeared shortly after Fig. 3c. The peak of the bloom is located near but outside the $10 \%$ ice contour, which makes it easily observable from satellite. Low chlorophyll values are visible between the main patch of the bloom and the sea-ice. This could indicate that in this region the bloom onset occurs in open-water; however, the chlorophyll estimates may be biased low due to the adjacency effect, whereby reflections from nearby ice affect the brightness of an image pixel (Bélanger et al., 2007). In any case, the bloom terminates at $20-100 \mathrm{~km}$ behind the retreating ice edge.

A Hovmöller diagram (Fig. 3d) shows the evolution of the bloom at $69^{\circ} \mathrm{N}$, based on daily chlorophyll and sea-ice data. The bloom lifetime does not exceed 20 days locally but over its whole course its duration is of the order of 2-3 months. The uncertainty regarding its duration comes both from the missing data between days 190 and 215, and from the choice of a chlorophyll threshold to define the bloom. Indeed, 
although the bloom clearly weakens as it moves westward, the chlorophyll values in the vicinity of the ice edge remain above a level of $0.5 \mathrm{mg} \mathrm{m}^{-3}$, before finally decreasing to an open-water background value after a few weeks. The exception is near the coast where chlorophyll remains moderately high all the year round (though, again, this may be confounded by CDOM contamination). The bloom starts approximately at the time when the ice concentration falls below $10 \%$, though the combined effect of sea-ice and clouds means that the first valid pixel often coincides with a bloom situation (concentration $>0.5 \mathrm{mg} \mathrm{m}^{-3}$ ) as can be seen on vertical sections of the Hovmöller diagram. On the eastern side $\left(54-56^{\circ} \mathrm{W}\right)$ there is a larger lag between ice retreat and blooms, making the classification as to whether open ocean or ice-edge bloom unclear. Such delayed blooms principally occur when the ice-edge retreat has stagnated. A more typical ice-edge bloom then develops once the retreat recommences.

\section{Synthetic view of the blooms at the pan-Arctic level}

The transient aspect of ice-edge blooms and their timing, strongly related to sea-ice melt, make them difficult to detect in monthly averages of satellite data. An alternative approach consists in producing a composite figure in which each pixel corresponds to the MIZ period locally, independent of its neighbours (Arrigo et al., 2008; Pabi et al., 2008). Such a composite can span a period of several months. In practical terms for this study, ice-edge blooms have been assumed to occur up to 20 days after ice concentration becomes durably less than 10\% (see Sect. 2 and Fig. 1). Figure 4a shows the timing of the first ice-free day in that sense, for 2007, and this is used subsequently to delimit the MIZ period. Features such as ice-retreat path and overall ice-melt timing for all regions of the Arctic are visible.

Figure $4 \mathrm{~b}$ shows the chlorophyll level at the peak of the transient ice-edge bloom. Again, high coastal values on the Eurasian and western Canadian shelves are regarded cautiously due to significant riverine inputs with high CDOM loading. It is noticeable that blooms are almost ubiquitous in the Arctic. In particular, Baffin Bay and the whole Canadian Archipelago, Barents Sea, Greenland Sea, Beaufort and Chukchi Sea, as well as the Russian Seas commonly experience strong $\left(1-10 \mathrm{mg} \mathrm{m}^{-3}\right)$ blooms. Taking the mean or median of the chlorophyll levels during the MIZ period smoothes the picture but does not change it qualitatively, nor does the choice of a 15- or 20-day MIZ period.

Missing data is a major issue with remote sensing in high latitudes, especially for ice-edge blooms. Even with clear sky conditions, partial sea-ice cover (where a remotely-sensed pixel contains both open water and sea-ice) may hide the first phase of the bloom or sometimes its peak, leading to underestimation. The impact of sea-ice is difficult to assess without in situ data, but clouds or fog can be monitored by
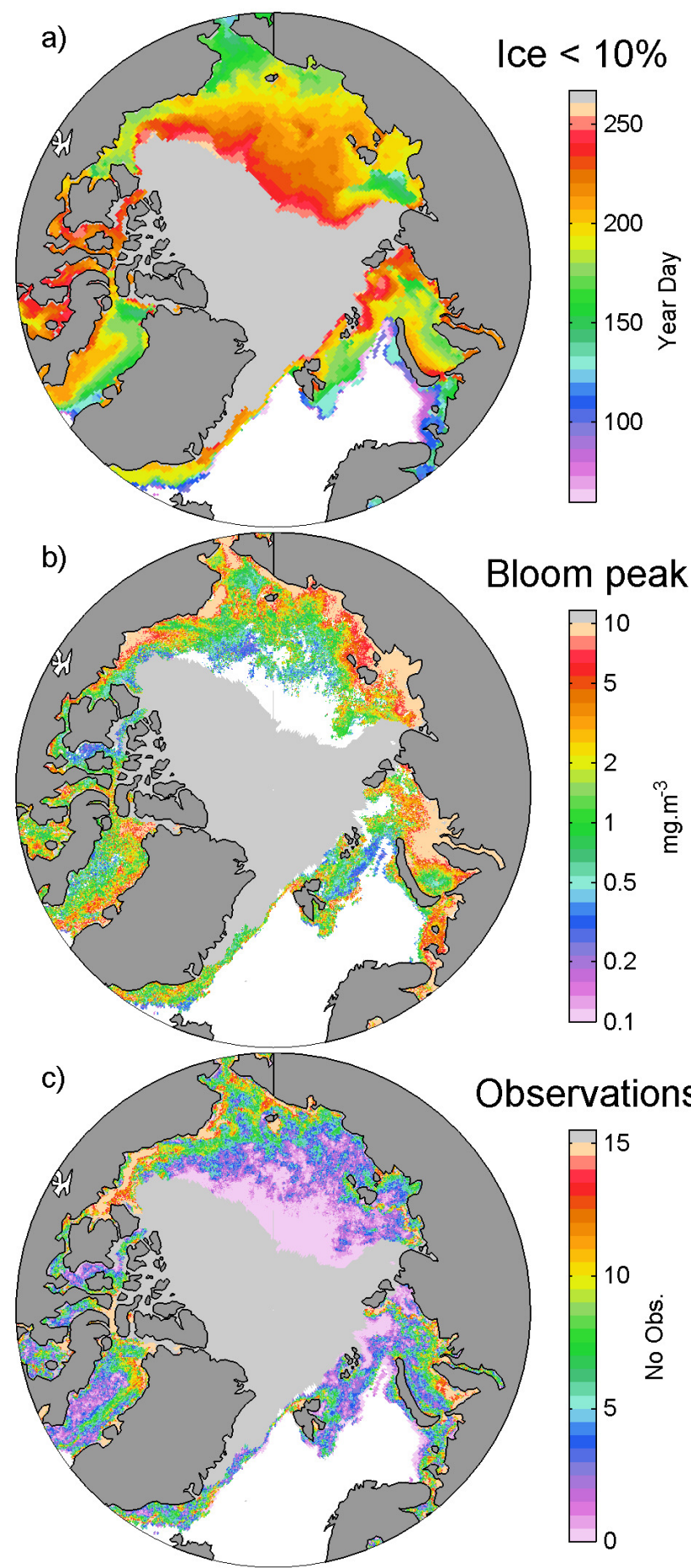

Fig. 4. Summary statistics for whole Arctic during 2007. The land mask is shown in dark grey, light grey areas correspond to permanent sea-ice cover, and white areas to open-ocean or missing data. (a) First day of the year that is durably ice-free. (b) Maximum chlorophyll concentration attained within the moving MIZ. (c) Number of valid SeaWiFS chlorophyll observations within the MIZ. 


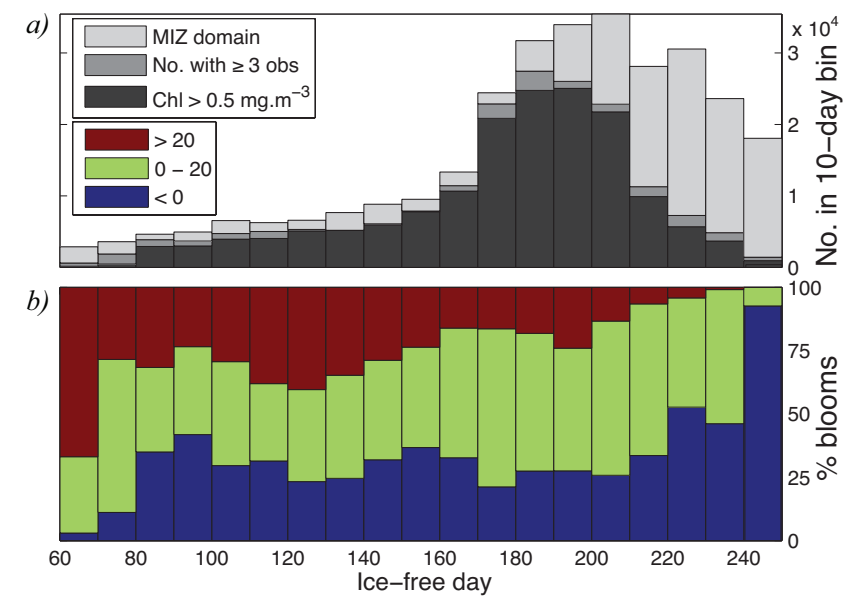

Fig. 5. Summary statistics for whole Arctic during 2007. (a) Number of MIZ pixels that become ice-free on a given day (light grey); pixels with more than 3 valid chlorophyll observations (dark grey); and those classified as a bloom (black). (b) For adequately observed blooms in MIZ, the percentage of them showing peak occurring before durably ice-free $(<10 \%)$ conditions (blue); within 0-20 days of melt period (green); or later (red).

noting the number of valid chlorophyll data points in the MIZ period (Fig. 4c). In this way it is found that around half of the pixels have at least 3 observations during the MIZ period and allow detection of the blooms. However, poor coverage, such as in the high Arctic $\left(150^{\circ}-210^{\circ} \mathrm{E}\right)$ or in central Baffin Bay, coincides with areas of apparently lower peak chlorophyll concentration. This often corresponds to cases where the first valid data arrive almost at the end of the MIZ period as defined above, and therefore find post-bloom conditions. In the high Arctic, the strongly stratified environment and associated low nutrient concentrations may explain the absence of a bloom. Alternatively, since the pack ice partly breaks during summer, light should reach the ocean surface and potentially allow phytoplankton growth and nutrient exhaustion before the first data are collected, even though there is still too much ice for bloom detection by remote sensing. Nonetheless, given the absence of reliable observations in these regions it is not clear whether there is really minimal growth (partly engendered by lack of nutrients) or that there is a rapid and short-lived bloom that is hidden by clouds, fog or sea-ice. This underlines a limitation of satellite data in that the apparent absence of a bloom does not mean that one did not occur.

The frequency of occurrence of ice-edge blooms in 2007 is quantified in Fig. 5a. The melt season spans from day 60 in the Atlantic sector to day 250 at high latitudes (see Fig. 4a), with the majority of the melting occurring from June onwards. To identify an ice-edge bloom, we require a minimum of 3 valid chlorophyll observations within the MIZ period, and that at least one exceeds a bloom threshold of $0.5 \mathrm{mg} \mathrm{m}^{-3}$. Moreover, we apply a coastal mask to diminish the impact of CDOM contamination. Of those points adequately observed, $89 \%$ fulfil the latter criterion. If the MODIS sensor is used instead of SeaWiFS, a more conservative value of $77 \%$ is found, due to the combined effects of fewer observations (as MODIS has a narrower swath) and lower chlorophyll estimates (as MODIS is biased lower than SeaWiFS) that decrease the likelihood of observations exceeding the $0.5 \mathrm{mg} \mathrm{m}^{-3}$ threshold (see Sect. 2). For $\sim 30 \%$ of points with recorded blooms the first observation is the highest, indicating that the bloom probably peaked before the ice concentration durably reduced to below $10 \%$, while a further 52\% show the chlorophyll peaking in the MIZ period. Mundy et al. (2009) report that epontic algae growing on the underside of sea-ice may initiate a bloom before ice-melt has occurred, but not all such species will survive and prosper within the water. The remainder have values increasing still after the end of the MIZ and may be due to slow development, to becoming part of an open-water bloom, to being downstream of the Bering Strait (which has high productivity year round) or to CDOM contamination (most likely in the Russian seas). Indeed, nearly half the blooms have terminated (decreased below $0.5 \mathrm{mg} \mathrm{m}^{-3}$ ) within the MIZ period. The above values are averages over the whole year, but separation into different melt periods (Fig. 5b) shows pre-melt blooms are uncommon early on (insufficient light) and latepeak blooms rare after day 230, when growth conditions are propitious but the period ice-free may be only 20 days.

We now consider primary production in the Arctic basin, and the contribution made by ice-edge blooms. There are a number of different algorithms for estimating primary production from remotely-sensed variables such as sea surface chlorophyll. However, as most were developed for globalscale applications and none are well-validated for the Arctic region, here we use a simple and commonly used one, the vertically generalised production model (VGPM; Behrenfeld and Falkowski, 1997). This algorithm estimates the production of organic matter based on surface chlorophyll, photosynthetically available radiation (PAR), sea surface temperature and day length. Because of the considerable uncertainties involved in estimating Arctic productivity in this way, which stem from both the input data and the VGPM's biological assumptions, we use this algorithm for illustrative purposes only. Appendix A describes estimates made using alternative algorithms that are broadly in agreement with the VGPM results. Figure 6a shows the resulting total primary production for the seasonally-covered ice region for 2007. Unsurprisingly, production is greatest in coastal waters and more southerly areas where the ice-free period is of greatest duration. To estimate the importance of ice-edge blooms, Fig. $6 \mathrm{~b}$ shows the ratio of mean production rate in the first 20 days after ice retreat to that in the remainder of the icefree period. At higher latitudes, close to the permanent seaice, the MIZ period is more productive, often significantly so, although with considerable variability. One source of this variability is the date on which ice cover is first lost, and the duration of ice-free conditions. 


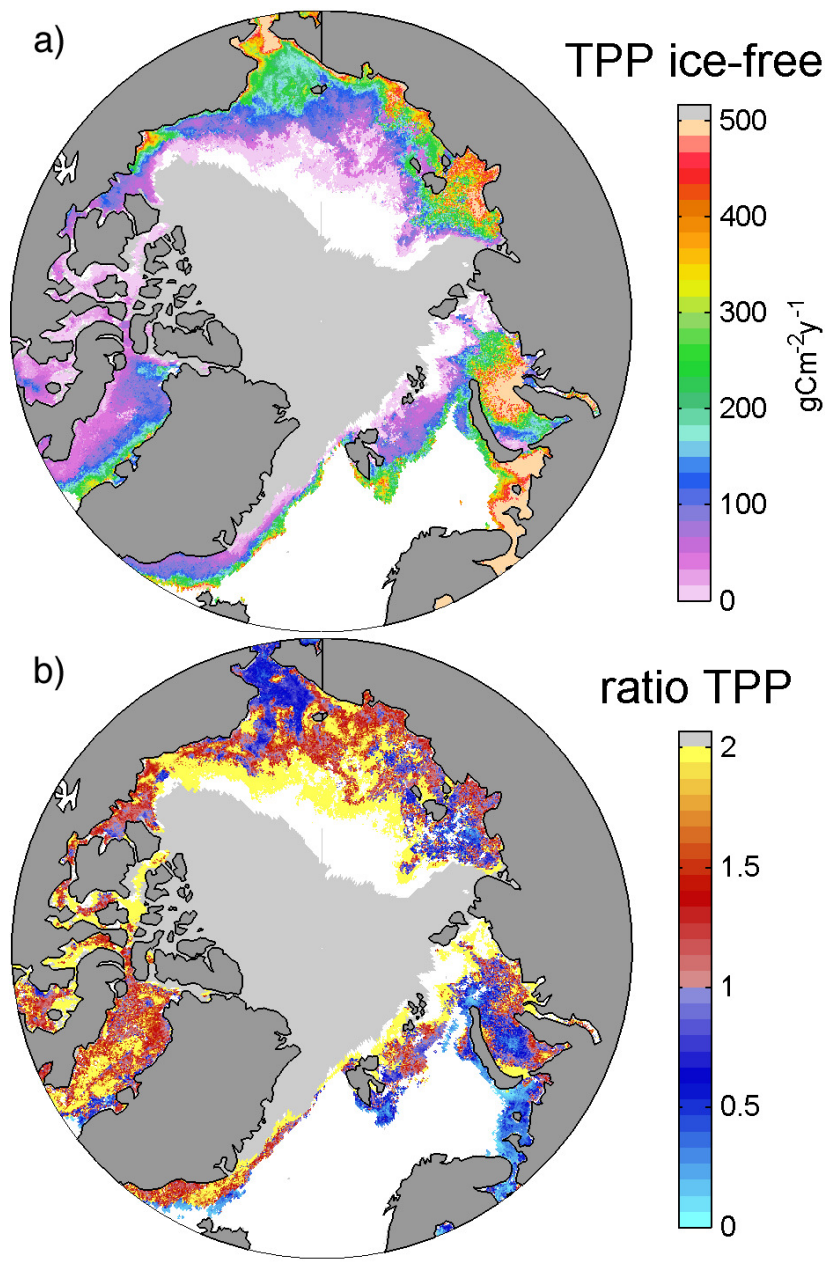

Fig. 6. Summary statistics for whole Arctic during 2007. (a) Total vertically-integrated primary production for the seasonal ice zone for the full year. (b) Ratio of average production rate in MIZ period to that for the rest of the ice-free period. Warmer colours (redyellow) indicate regions where the MIZ exhibits higher rates of productivity than the rest of the year. In both panels, the land mask is shown in dark grey, light grey areas correspond to permanent seaice cover, and white areas to open-ocean or missing data.

An important caveat is that phytoplankton mostly occur in the upper mixed layer during the initial ice-edge bloom, but may subsequently occur below the mixed layer later in the summer open-water period, at a depth which prevents remote detection by satellite. Consequently, estimates of both phytoplankton abundance and associated primary production may be systematically biased in favour of ice-edge blooms. On the other hand, phytoplankton at depth will experience much-decreased PAR availability, and consequently may be expected to have lower growth rates and be less productive. The application of VGPM here effectively assumes that, in the absence of more detailed supporting data, these two biases approximately cancel.

\section{Conclusions and perspectives}

Satellite ocean colour sensors are the only instruments that provide a synoptic-scale view of ice-edge phytoplankton blooms and their propagation following the receding sea-ice. Although noted in a number of hydrographic surveys, their occurrence has never before been fully quantified. However, satellites suffer from gaps in the data record due to clouds, fog and (more intrinsically) sea-ice. Of points becoming durably ice-free only $\sim 50 \%$ have at least 3 observations in the succeeding 20 days, but $89 \%$ of these cases showed a bloom in that period. This value carries some uncertainty due to limitations of remote-sensing in the Arctic (in particular sub-pixel contamination of sea-ice; e.g. Bélanger et al., 2007; Wang and Shi, 2009), but another sensor with a different chlorophyll retrieval algorithm and less data coverage also yielded a very high occurrence frequency $(77 \%$; see Sect. 5). A greater occurrence of blooms may be masked by the long data gaps in the MIZ period. For half of the points showing an ice-edge bloom, it terminates within 20 days indicating the rapid response needed by those wishing to sample it directly.

For regions of early ice melt, MIZ blooms are less common, and their contribution to annual primary productivity is diminished by the long periods available for open-water blooms. However, at high latitudes mean productivity rates during the MIZ period may be 1.5-2 times greater than those in open-water conditions. Note, though, that the productivity algorithms used here are likely to be poorly-optimised for estimating Arctic primary production. While MIZ blooms occur in thin, highly stratified surface layers and produce readily discernible chlorophyll signals, open-water blooms are spread across thicker mixed layers that result in a weaker surface signal, while deep blooms at the pycnocline produce no detectable surface signal at all (Martin et al., 2010). These factors may act to exaggerate the magnitude of the MIZ blooms relative to primary production later in the Arctic season.

Understanding ice-edge blooms and their timing is valuable to identify links with higher trophic levels and, eventually, fish stocks. For instance, Hunt et al. (2002) showed that either top-down or bottom-up regimes can exist in the southern Bering Sea, depending on the timing of the ice-retreat and therefore blooming. Water temperature at the time of the bloom may limit or favour zooplankton larvae growth and survival. In Hunt et al. (2002), late ice-melt was related to early blooming while early melt found late blooms. In our study, blooms closely follow the ice retreat leading to a more direct relationship. The implication of inter-annual changes in the timing of this retreat for fish recruitment needs further investigation.

Changes in ice melt driven by anthropogenic climate change may lead to a seasonally ice-free Arctic Ocean, with substantially different heat and freshwater budgets and stratification (Serreze et al., 2007). This could lead to ice-edge 

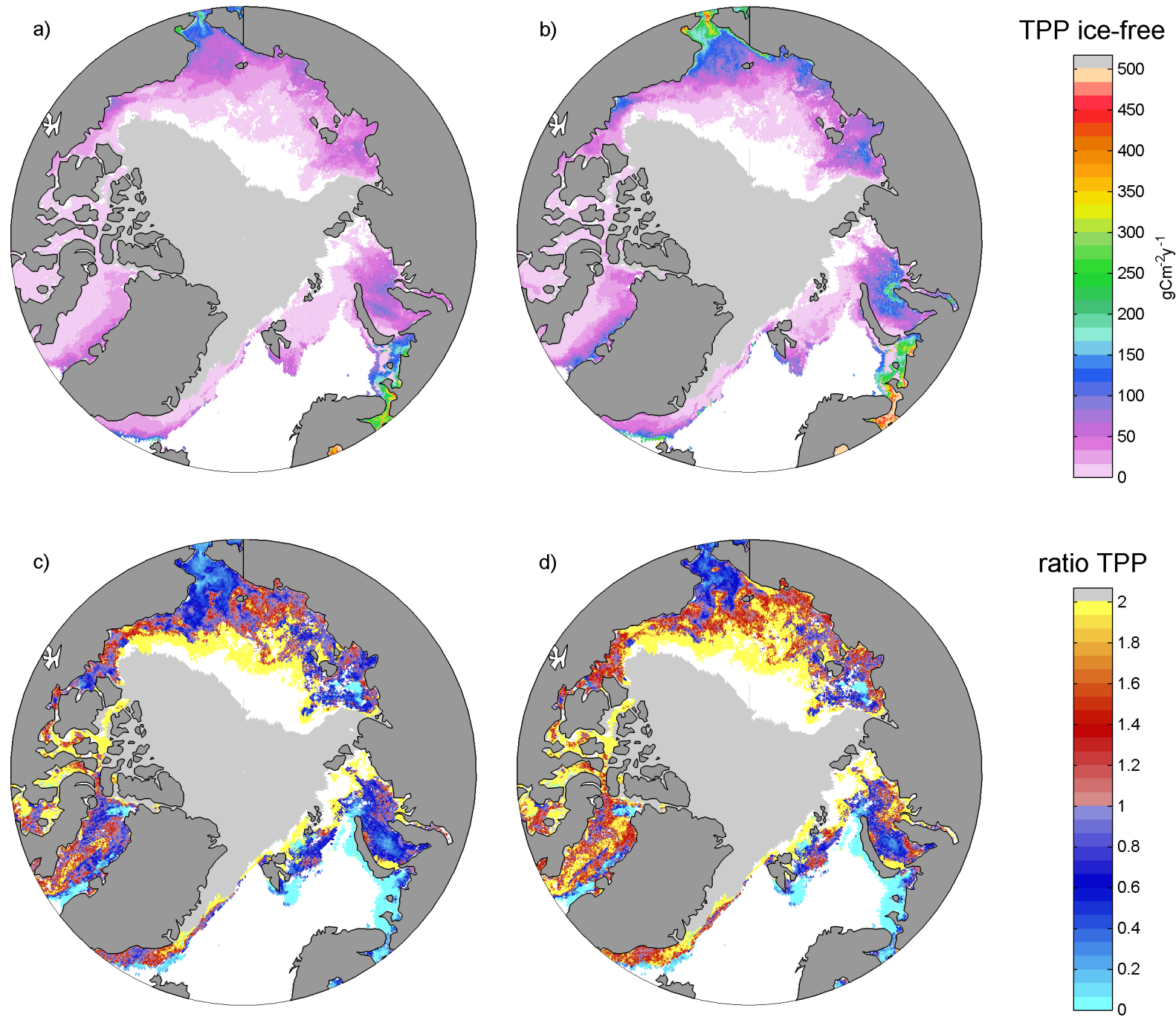

Fig. A1. Alternative algorithms for estimating Arctic primary production. Panels (a) and (b) show total vertically-integrated primary production for the seasonal ice zone for the full year for the Carr (2002) and Marra et al. (2003) algorithms respectively. Panels (c) and (d) show the corresponding ratios of average production rate in MIZ period to that for the rest of the ice-free period. In these latter panels, warmer colours (red-yellow) indicate regions where the MIZ exhibits higher rates of productivity than the rest of the year. In all panels, the land mask is shown in dark grey, light grey areas correspond to permanent sea-ice cover, and white areas to open ocean or missing data.

blooms propagating over much greater distances as the melt season becomes longer. Whether these blooms become more intense and prolonged and ultimately increase total Arctic primary production will depend on the fate of the Arctic halocline that currently isolates the surface euphotic layer from the deep nutrient pool. The balance between projected increased riverine input (Peterson et al., 2002), modified ice transport (Serreze et al., 2007), increase in storms (Yang et al., 2004) and internal waves eroding the halocline (Rainville and Woodgate, 2009) will determine the future characteristics of blooms and primary production in the Arctic Ocean.

\section{Appendix A}

In the preceding analysis of Arctic primary productivity, we employed a widely-used algorithm, the VGPM (Behrenfeld and Falkowski, 1997), to estimate the seasonal pattern and 
distribution of production. This algorithm, in common with most comparable algorithms, was developed for the global ocean, and has not been specifically optimised for Arctic conditions. To assess the significance of our choice, here we employ two further algorithms to separately calculate Arctic primary production.

The algorithms used for this analysis are Carr (2002) and Marra et al. (2003). Both utilise the same (or fewer; Carr, 2002) spatio-temporal input fields as the VGPM algorithm: surface chlorophyll $\left(\mathrm{mg} \mathrm{m}^{-3}\right)$, photosynthetically available radiation $\left(\mathrm{E} \mathrm{m}^{-2} \mathrm{~d}^{-1}\right)$, sea surface temperature $\left({ }^{\circ} \mathrm{C}\right)$ and fractional day length $(-)$.

Figure A1 reproduces the fields shown in Fig. 6 but for these two further algorithms. As panels a and $b$ show, neither algorithm finds the Arctic as productive as the VGPM, particularly Carr (2002). Nonetheless, both algorithms concur with the VGPM in finding high productivity along Arctic coastlines, particularly in the Barents and Chukchi seas, although neither algorithm estimates as high values for the Kara and Laptev seas as the VGPM does.

Although the new algorithms estimate significantly lower production in the Arctic, both indicate comparable importance of the MIZ for the Arctic growing season. As in Fig. 6, panels (c) and (d) show the ratio of MIZ productivity to that of the rest of the ice-free period. Both algorithms agree with the VGPM in finding large regions of the Arctic in which the MIZ experiences significantly higher productivity.

In summary, though none of the algorithms examined here is tailored for the Arctic Ocean, and they disagree about the absolute magnitude and distribution of primary productivity, they broadly agree on the importance of MIZ production.

Acknowledgements. We are grateful to the NSIDC for the provision of sea-ice concentration data, to NASA Goddard Space Flight Center for the SeaWiFS and MODIS chlorophyll data, and to Stephanie Henson (NOC) for coding the primary productivity algorithms used in our analysis. We are also grateful to two anonymous referees for their detailed comments on an earlier version of this manuscript.

Edited by: E. Boss

\section{References}

Alexander, V. and Niebauer, H. J.: Oceanography of the Eastern Bering Sea ice-edge zone in spring, Limnol. Oceanogr., 26, 1111-1125, 1981.

Arrigo, K. R. and van Dijken, G. L.: Annual cycles of sea ice and phytoplankton in Cape Bathurst polynya, southeastern Beaufort Sea, Canadian Arctic, Geophys. Res. Lett., 31, L08304, doi:10.1029/2003GL018978, 2004.

Arrigo, K. R., van Dijken, G. L., and Bushinsky, S.: Primary production in the Southern Ocean, 1997-2006, J. Geophys. Res., 113, C08004, doi:10.1029/2007JC004551, 2008.

Behrenfeld, M. J. and Falkowski, P. G.: Photosynthetic rates derived from satellite-based chlorophyll concentration, Limnol. Oceanogr., 42, 1-20, 1997.
Bélanger, S., Ehn, J. K., and Babin, M.: Impact of sea ice on the retrieval of water-leaving reflectance, chlorophyll a concentration and inherent optical properties from satellite ocean color data, Remote Sens. Environ., 111, 51-68, doi:10.1016/j.rse.2007.03.013, 2007.

Carr, M.-E.: Estimation of potential productivity in Eastern Boundary Currents using remote sensing, Deep-Sea Res. II, 49, 59-80, 2002.

Comiso, J.: Bootstrap Sea Ice Concentrations from NIMBUS-7 SMMR and DMSP SSM/I, 1998-2007, National Snow and Ice Data Center, Boulder, Colorado USA, (updated 2008), 1999.

Cota, G. F., Wang, J., and Comiso, J. C.: Transformation of global satellite chlorophyll retrievals with a regionally tuned algorithm, Remote Sens. Environ., 90, 373-377, doi:10.1016/j.rse.2004.01.005, 2004.

Gregg, W. W. and Casey, N. W.: Global and regional evaluation of the SeaWiFS chlorophyll data set, Remote Sens. Environ., 93, 463-479, doi:10.1016/j.rse.2003.12.012, 2004.

Hegseth, E. N. and Sundfjord, A.: Intrusion and blooming of Atlantic phytoplankton species in the high Arctic, J. Mar. Syst., 74, 108-119, doi:10.1016/j.jmarsys.2007.11.011, 2008.

Hill, V., Cota, G. F., and Stockwell, D.: Spring and summer phytoplankton communities in the Chukchi and Eastern Beaufort Seas, Deep-Sea Res. Pt. II, 52, 3369-3385, doi:10.1016/j.dsr2.2005.10.010, 2005.

Hunt, G. L., Stabeno, P., Walters, G., Sinclair, E., Brodeur, R. D., Napp, J. M., and Bond, N. A.: Climate change and control of the southeastern Bering Sea pelagic ecosystem, Deep-Sea Res. Pt. II, 49, 5821-5853, doi:10.1016/S0967-0645(02)00321-1, 2002.

Klein, B., LeBlanc, B., Mei, Z.-P., Beret, R., Michaud, J., Mundy, C. J., von Quillfeldt, C. H., Garneau, M.-E., Roy, S., Gratton, Y., Cochran, J. K., Bélanger, S., Larouche, P., Pakulski, J. D., Rivkin, R. B., and Legendre, L.: Phytoplankton biomass, production and potential export in the North Water, Deep-Sea Res. Pt. II, 49, 4983-5002, doi:10.1016/S0967-0645(02)00174-1, 2002.

Kögeler, J. and Rey, F.: Ocean colour and the spatial and seasonal distribution of phytoplankton in the Barents Sea, Int. J. Remote Sens., 20, 1303-1318, 1999.

Luchetta, A., Lipizer, M., and Socal, G.: Temporal evolution of primary production in the central Barents Sea, J. Mar. Syst., 27, 177-193, doi:10.1016/S0924-7963(00)00066-X, 2000.

Marra, J., Ho, C. and Trees, C. C.: An alternative algorithm for the calculation of primary productivity from remote sensing data, Lamont-Doherty Earth Observatory, Technical Report \#LDEO2003-1, 27 pp. (unpublished manuscript), 2003.

Martin, J. Tremblay, J.-E., Gagnon, J., Tremblay, G., Lapoussir, A, Jose, C., Poulin, M., Gosselin, M., Gratton, Y., and Michel, C.: Revelance, structure and properties of subsurface chlorophyll maxima in Canadian Arctic waters, Mar. Ecol. Prog. Ser., 412, 69-84, doi:10.3354/meps08666, 2010.

Matsuoka, A., Saitoh, S., and Shimada, K.: A new approach for ocean color algorithm in Case 2 water using bio-optical field measurements in the western Arctic Ocean, Proc. SPIE Int. Soc. Opt. Eng., 5977, 77-87, 2005.

Maynard, N. G.: Coastal Zone Color Scanner imagery in the margical ice zone, Mar. Tech. Soc., 20, 14-27, 1986.

Maynard, N. G. and Clark, D. K.: Satellite color observations of spring blooming in Bering Sea shelf waters during the ice edge retreat in 1980, J. Geophys. Res., 92, 7127-7139, 1987. 
Mitchell, B. G., Brody, E. A., Yeh, E.-N., McClain, C., Comiso, J. C., and Maynard, N. G.: Meridional zonation of the Barents Sea ecosystem inferred from satellite remote sensing and in situ bio-optical observations, Polar Research, 10, 147-162, 1991.

Mundy, C. J., Gosselin, M., Ehn, J., Gratton, Y., Rossnagel, A., arber, D. G., Martin, J., Tremblay, J.-E., Palmer, M. Arrigo, K. R., Darnis, G., Fortier, L., Else, B., and Papakyriakou, T.: Contribution of under-ice primary production to an ice-edge upwelling phytoplankton bloom in the Canadian Beaufort Sea, Geophys. Res. Lett., 36, L17601, doi:10.1029/2009GL038837, 2009.

Niebauer, H.: Bio-physical oceanographic interactions at the edge of the Arctic ice pack, J. Mar. Syst., 2, 209-232, doi:10.1016/0924-7963(91)90025-P, 1991.

Niebauer, H. J., Alexander, V., and Henrichs, S. M.: A time-series study of the spring bloom at the Bering Sea ice edge I. Physical processes, chlorophyll and nutrient chemistry, Cont. Shelf Res., 15, 1859-1877, doi:10.1016/0278-4343(94)00097-7, 1995.

Pabi, S., van Dijken, G. L., and Arrigo, K. R.: Primary production in the Arctic Ocean, 1998-2006, J. Geopys. Res., 113, C08005, doi:10.1029/2007JC004578, 2008.

Peterson, B. J., Holmes, R. M., McClelland, J. W., Vorosmarty, C. J., Lammers, R. B., Shiklomanov, A. I., and Rahmstorf, S.: Increasing river discharge to the Arctic Ocean, Science, 298, 21712173, doi:10.1126/science.1077445, 2002.

Rainville, L. and Woodgate, R. A.: Observations of internal wave generation in the seasonally ice-free Arctic, Geophys. Res. Lett., 36, L23604, doi:10.1029/2009GL041291, 2009.

Sakshaug, E.: Primary and secondary production in the Arctic Seas, in: The organic carbon cycle in the Arctic Ocean, edited by: Stein, R. and Macdonald, R. W., Springer-Verlag, Berlin, Germany, 2004.

Sakshaug, E. and Skjoldal, H.: Life at the ice edge, Ambio, 18, 60-67, 1989.

Serreze, M. C., Holland, M. M., and Stroeve, J.: Perspectives on the Arctic's shrinking sea-ice cover, Science, 315, 1533-1536, doi:10.1126/science.1139426, 2007.

Smith, W. O. and Nelson, D. M.: Phytoplankton bloom produced by a receding ice edge in the Ross Sea: spatial coherence with the density field, Science, 227, 163-166, 1985.
Smith, W. O., Gosselin, M., Legendre, L., Wallace, D., Daly, K., and Kattner, G.: New production in the Northeast Water Polynya: 1993, J. Mar. Syst., 10, 199-209, doi:10.1016/S09247963(96)00067-X, 1997.

Sukhanova, I. N., Flint, M. V., Pautova, L. A., Stockwell, D. A., Grebmeier, J. M., and Sergeeva, V. M.: Phytoplankton of the western Arctic in the spring and summer of 2002: Structure and seasonal changes, Deep-Sea Res. Pt. II, 56, 1223-1236, doi:10.1016/j.dsr2.2008.12.030, 2009.

Sverdrup, H. U.: On conditions for the vernal blooming of phytoplankton, Journal du Conseil, 18, 287, doi:10.1093/icesjms/18.3.287, 1953.

Tremblay, J. and Gagnon, J.: The effects of irradiance and nutrient supply on the productivity of Arctic waters: a perspective on climate change, in: Influence of Climate Change on the Changing Arctic and Sub-Arctic Conditions, edited by: Hihoul, J. C. J. and Kostianoy, A., Springer-Verlag, Berlin, Germany, 2009.

Tremblay, J., Michel, C., Hobson, K., Gosselin, M., and Price, N.: Bloom dynamics in early opening waters of the Arctic Ocean, Limnol. Oceanogr., 51, 900-912, 2006.

Wang, J. and Cota, G. F.: Remote-sensing reflectance in the Beaufort and Chukchi seas: Observations and models, Appl. Optics, 42, 2754, doi:10.1364/AO.42.002754, 2003.

Wang, M. and Shi, W.: Detection of ice and mixed ice-water pixels for MODIS ocean color data processing, IEEE Trans. Geosci. Rem. Sens., 47, 2510-2518, 2009.

Wassmann, P., Carroll, J., and Bellerby, R.: Carbon flux and ecosystem feedback in the northern Barents Sea in an era of climate change: An introduction, Deep-Sea Res. Pt. II, 55, 2143-2153, doi:10.1016/j.dsr2.2008.05.025, 2008.

Worby, A. and Comiso, J.: Studies of the Antarctic sea ice edge and ice extent from satellite and ship observations, Remote Sens. Environ., 92, 98-111, doi:10.1016/j.rse.2004.05.007, 2004.

Yang, J., Comiso, J., Walsh, D., Krishfield, R., and Honjo, S.: Storm-driven mixing and potential impact on the Arctic Ocean, J. Geophys. Res., 109, C04008, doi:10.1029/2001JC001248, 2004. 